\title{
Long term follow-up of ventilated patients with thoracic restrictive or neuromuscular disease
}

\author{
Dina Brooks PhD MSc BSc ${ }^{1,3}$, James De Rosie BSc RCPT ${ }^{3}$, Margaret Mousseau BSc ${ }^{1}$, \\ Monica Avendaño MD FCCP FRCPC ${ }^{2,3}$, Roger S Goldstein MB ChB FCCP FRCPC $1,2,3$
}

\begin{abstract}
D Brooks, J De Rosie, M Mousseau, M Avendaño, RS Goldstein. Long term follow-up of ventilated patients with thoracic restrictive or neuromuscular disease. Can Respir J 2002;9(2):99-106.
\end{abstract}

OBJECTIVE: To evaluate the long term effects of home mechanical ventilation (HMV) on pulmonary function, nighttime gas exchange, daytime arterial blood gases, sleep architecture and functional exercise capacity ( $6 \mathrm{~min}$ walk). Patients with respiratory failure attributable to thoracic restrictive disease (TRD) (kyphoscoliosis) or neuromuscular disease (NMD) were assessed, ventilated, trained and followed in a dedicated unit for the care of patients requiring long term ventilation.

DESIGN: All patients admitted for home ventilation training since 1988 were reviewed. Measurements of lung function, gas exchange during wakefulness and sleep, as well as functional exercise capacity, were recorded before and immediately after the establishment of HMV. Measurements were repeated one to two years, five years and eight to 10 years later.

PATIENTS: Seventy-four individuals with TRD or NMD who completed the home ventilation training program and continued with HMV during all or part of the day for at least one year were studied.

RESULTS: Forty patients had TRD. The characteristics of these patients were (mean \pm SE) as follows: age $58 \pm 2.4$ years; vital capacity (VC) $27 \% \pm 1.6 \%$ predicted, forced expiratory volume in $1 \mathrm{~s}\left(\mathrm{FEV}_{1}\right) 25 \% \pm 1.5 \%$ predicted; $\mathrm{FEV}_{1} /$ forced VC (FVC) $78 \% \pm 1.8 \%$. Thirty-four patients had NMD. The characteristics of these patients were as follows: age $44 \pm 3.1$ years; $\mathrm{VC} 41 \% \pm 4.9 \%$ predicted, $\mathrm{FEV}_{1} 44 \pm 5.3 \%$ predicted;
$\mathrm{FEV}_{1} / \mathrm{FVC} 83 \% \pm 4.2 \%$. There was a significant improvement in distance walked in $6 \mathrm{~min}$ (maximum change $51.2 \mathrm{~m}$ in patients with NMD and $93.0 \mathrm{~m}$ in patients with TRD), daytime partial pressure of arterial carbon dioxide (maximum change $12.9 \mathrm{mmHg}$ in patients with NMD and $10.4 \mathrm{mmHg}$ in patients with TRD) and nighttime partial pressure of arterial carbon dioxide (maximum change $11.7 \mathrm{mmHg}$ in patients with $\mathrm{NMD}$ and $18.0 \mathrm{mmHg}$ in patients with TRD) over time $(\mathrm{P} \leq 0.004)$. Ventilation resulted in an improvement in partial pressure of arterial oxygen in patients with TRD $(68.1 \pm 2.8 \mathrm{mmHg}$ to $80.1 \pm 3.5 \mathrm{mmHg})$ and in patients with NMD $(52.9 \pm 1.7 \mathrm{mmHg}$ to $65.3 \pm 2.1 \mathrm{mmHg})$, although the change was not statistically significant in patients with NMD ( $P=0.001$ in patients with TRD; $P=0.105$ in patients with NMD). The improvement after ventilation was maintained over several years. Sleep efficiency $(75 \% \pm 18 \%, 79 \% \pm 2.2 \%)$, the arousal index $(13.4 \pm 13$ events/h, $28.2 \pm 17$ events/h) and the apnea-hypopnea index $(10.1 \pm 11.3$ events/h, $13.9 \pm 9.5$ events/h) did not change with time in either patients with TRD or patients with NMD, respectively $(\mathrm{P} \geq 0.5)$.

CONCLUSIONS: HMV was associated with sustained, long term improvements in nighttime and daytime gas exchange in patients with TRD and NMD. Function exercise capacity increased in patients with TRD and in a subgroup of ambulatory patients with NMD. In patients with TRD, these improvements were maintained for up to 10 years after HMV was established.

Key Words: Arterial blood gases; Home mechanical ventilation; Kyphoscoliosis; Neuromuscular disease; Walk test

Résumé à la page suivante

Departments of ${ }^{1}$ Physical Therapy and ${ }^{2}$ Medicine, Faculty of Medicine, University of Toronto, and ${ }^{3}$ West Park Healthcare Centre, Toronto, Ontario Correspondence: Dr Roger Goldstein, Respiratory Medicine, West Park Healthcare Centre, 82 Buttonwood Avenue, Toronto, Ontario M6M 2J5. Telephone 416-243-3631, fax 416-243-8947, e-mail rgoldstein@westpark.org 


\section{Suivi à long terme de patients ventilés, atteints d'une maladie neuro-musculaire ou thoracique restrictive}

OBJECTIF : Évaluer les effets à long terme de la ventilation artificielle à domicile (VAD) sur le fonctionnement pulmonaire, les échanges gazeux la nuit, la gazométrie du sang artériel le jour, la structure du sommeil et la capacité fonctionnelle d'effort (marche de $6 \mathrm{~min}$ ). Des patients atteints d'insuffisance respiratoire due à une déformation restrictive du thorax (DRT) (cypho-scoliose) ou à une maladie neuro-musculaire (MNM) ont été évalués, ventilés, formés et suivis dans un service spécialisé en soins aux patients ayant besoin d'une ventilation prolongée.

MÉTHODE : Tous les patients admis depuis 1988 dans un programme de formation sur la ventilation à domicile ont été examinés. Nous avons procédé à des mesures du fonctionnement pulmonaire, des échanges gazeux à l'état de veille et durant le sommeil et de la capacité fonctionnelle d'effort avant et immédiatement après la mise en œuvre de la VAD. Il y a eu reprise des mesures au bout de 1 à 2 ans, de 5 ans et de 8 à 10 ans. PATIENTS : Soixante-quatorze patients atteints d'une DRT ou d'une MNM, qui avaient terminé le programme de formation sur la ventilation à domicile et qui avaient poursuivi le traitement en tout ou en partie le jour pendant au moins un an ont participé à l'étude.

RÉSULTATS : Quarante patients souffraient d'une DRT; ils présentaient

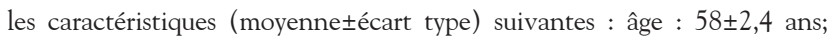
capacité vitale (CV) : 27 $\pm 1,6 \%$ du volume prévu; volume expiratoire maximal en une seconde (VEMS) : 25 $\pm 1,5 \%$ du volume prévu; VEMS/capacité vitale forcée $(C V F): 78 \pm 1,8 \%$. Trente-quatre patients souffraient d'une MNM; ils présentaient les caractéristiques suivantes : âge : $44 \pm 3,1$ ans;
CV : 41 $\pm 4,9 \%$ du volume prévu; VEMS : 44 $\pm 5,3 \%$ du volume prévu; VEMS/CVF : $83 \pm 4,2 \%$. Nous avons noté, dans le temps, une amélioration significative de la distance parcourue en 6 min (écart maximal : 51,2 m et $93 \mathrm{~m}$ chez les patients atteints respectivement d'une MNM et d'une DRT), de la pression partielle du gaz carbonique dans le sang artériel durant le jour (écart maximal : 12,9 $\mathrm{mm} \mathrm{Hg}$ et 10,4 $\mathrm{mm} \mathrm{Hg}$ chez les patients atteints respectivement d'une MNM et d'une DRT) et de la pression partielle du gaz carbonique dans le sang artériel durant la nuit (écart maximal : 11,7 mm Hg et $18,0 \mathrm{~mm} \mathrm{Hg}$ chez les patients atteints respectivement d'une MNM et d'une $\mathrm{DRT})(\mathrm{P} \leq 0,004)$. La ventilation a aussi permis une amélioration de la pression partielle de l'oxygène dans le sang artériel chez les patients présentant une DRT (de $68,1 \pm 2,8 \mathrm{~mm} \mathrm{Hg}$ à $80,1 \pm 3,5 \mathrm{~mm} \mathrm{Hg}$ ) et chez ceux qui souffraient d'une MNM (de 52,9 $\pm 1,7 \mathrm{~mm} \mathrm{Hg}$ à $65,3 \pm 2,1 \mathrm{~mm} \mathrm{Hg}$ ), mais l'écart s'est avéré non significatif dans ce dernier groupe $(\mathrm{P}=0,001$ et $\mathrm{P}=0,105$ chez les patients atteints respectivement d'une DRT et d'une MNM). L'amélioration observée après la ventilation s'est maintenue pendant plusieurs années. Toutefois, les paramètres suivants : l'efficacité du sommeil ( $75 \pm 18 \%, 79 \pm 2,2 \%)$, l'index d'éveil $(13,4 \pm 13$ événements/h, $28,2 \pm 17$ évén./h) et l'index d'apnée-hypopnée $(10,1 \pm 11,3$ évén./h, 13,9 $\pm 9,5$ évén./h) n'ont pas changé au fil du temps chez les patients présentant respectivement une DRT et une MNM $(\mathrm{P} \geq 0,5)$.

CONCLUSIONS : La VAD est associée à une amélioration prolongée des échanges gazeux diurnes et nocturnes chez les patients atteints d'une DRT ou d'une MNM. Il y a également amélioration de la capacité fonctionnelle d'effort chez les patients présentant une TRD et dans un sousgroupe de patients ambulatoires souffrant d'une MNM. Enfin, ces améliorations se sont maintenues jusqu'à dix ans après le début de la VAD chez les patients porteurs d'une DRT.
$\mathrm{M}$ echanical ventilation is one of the major reasons for admitting patients to the intensive care unit (ICU). It is also a reason for prolonging the ICU stay after the critical stage has been resolved. Home mechanical ventilation (HMV) was initiated during the poliomyelitis epidemics more than 50 years ago (1-6). A resurgence of interest has occurred in association with the increased number of patients who remain in the ICU simply because of their ventilator dependence. Advances in ventilator technology, improvements in home care services and pressures to reduce institutional costs have contributed to the increasing numbers of people being considered for HMV both in North America and in Europe (2,7-10).

Patients with chronic ventilatory failure associated with thoracic restrictive disease (TRD) (kyphoscoliosis) or neuromuscular disease (NMD) are known to derive benefit from long term ventilation in terms of improvements in blood gases and survival (1-6). As an important alternative to institutional care, HMV has improved the cost effectiveness of health care for the users by decreasing their morbidity and improving their health-related quality of life $(4,5,7)$.

HMV may be initiated in the ICU after an episode of acute respiratory failure in patients with minimal independent respiratory function, or it may be introduced electively for patients with progressive ventilatory insufficiency. The requirements for ventilation vary from intermittent (nocturnal) to continuous, based on the severity of the underly- ing respiratory condition. Long term ventilation may be provided noninvasively and is usually the preferred route. When noninvasive ventilation is no longer effective or if airway protection is required, ventilation can be safely established via a tracheostomy.

The purpose of the present study was to summarize the outcomes of patients with TRD and NMD who were trained in a dedicated unit for HMV and rehabilitation. Nighttime and daytime gas exchange, sleep architecture and functional exercise capacity (6 min walk) were measured at baseline (preventilation), and were repeated after one to two years, five years and eight to 10 years.

\section{Patients}

\section{PATIENTS AND METHODS}

Measurements from all patients with TRD or NMD admitted to a four-bed unit dedicated to the care of patients requiring HMV were summarized. Patients were accepted for home ventilation training provided that they were clinically stable, motivated to return to the community and had sufficient support to return home with HMV as part of their ongoing medical management. Some patients were ventilated at the time of their referral from an acute care centre, while others had been referred to the unit for elective ventilation. Most patients remained in the unit for two to four weeks, and received pulmonary rehabilitation to provide education, increase exercise capacity and stabilize their respiratory status. During this time, they and their 
TABLE 1

Mean \pm SE $(n)$ of sleep efficiency, and the arousal and apnea-hypopnea indexes in patients with thoracic restrictive disease (TRD) and neuromuscular disease (NMD)

\begin{tabular}{|c|c|c|c|c|c|c|}
\hline & $\begin{array}{c}\text { Sleep } \\
\text { efficiency } \\
\text { (TRD) (\%) }\end{array}$ & $\begin{array}{c}\text { Sleep } \\
\text { efficiency } \\
(N M D)(\%)\end{array}$ & $\begin{array}{c}\text { Arousal } \\
\text { index (TRD) } \\
\text { (events/h) }\end{array}$ & $\begin{array}{c}\text { Arousal } \\
\text { index (NMD) } \\
\text { (events/h) }\end{array}$ & $\begin{array}{l}\text { Apnea-hypopnea } \\
\text { index (TRD) } \\
\text { (events/h) }\end{array}$ & $\begin{array}{c}\text { Apnea-hypopnea } \\
\text { index (NMD) } \\
\text { (events/h) }\end{array}$ \\
\hline Baseline & $75.4 \pm 17.7(n=34)$ & $79.2 \pm 2.2(n=14)$ & $13.4 \pm 12.7(n=17)$ & $28.2 \pm 17.3(n=6)$ & $10.1 \pm 11.3(n=33)$ & $13.9 \pm 9.5(n=12)$ \\
\hline Ventilation established & $74.2 \pm 19.9(n=20)$ & $75.3 \pm 5.8(n=9)$ & $14.1 \pm 11.9(n=14)$ & $25.8 \pm 14.0(n=6)$ & $4.2 \pm 3.4(n=17)$ & $7.4 \pm 4.7(n=6)$ \\
\hline One to two years* & $76.4 \pm 12.3(n=25)$ & $71.8 \pm 5.5(n=14)$ & $15.3 \pm 15.3(n=19)$ & $20.4 \pm 3.0(n=12)$ & $4.6 \pm 4.7(n=20)$ & $9.2 \pm 3.2(n=12)$ \\
\hline Five years* & $76.9 \pm 18.8(n=11)$ & $\mathrm{N} / \mathrm{A}$ & $21.3 \pm 16.7(n=8)$ & N/A & $10.2 \pm 14.8(n=10)$ & $\mathrm{N} / \mathrm{A}$ \\
\hline Eight years* & $85.9 \pm 11.4(n=6)$ & $\mathrm{N} / \mathrm{A}$ & $10.3 \pm 4.8(n=6)$ & $\mathrm{N} / \mathrm{A}$ & $8.4 \pm 7.1(n=6)$ & $N / A$ \\
\hline $\mathrm{P}$ & 0.9 & 0.5 & 0.9 & 0.8 & 0.9 & 0.8 \\
\hline
\end{tabular}

${ }^{*}$ After ventilation was established. N/A Not available

caregivers were trained in HMV. Care was provided by a multidisciplinary team that included physicians, respiratory therapists, physical therapists, nurses, occupational therapists and a social worker. Patients learned about their medical condition, as well as about their ventilator, interfaces and accessories. Group teaching was supplemented by individual sessions as required. Before discharge, patients were requested to demonstrate their proficiency in ventilator care and self-management. Ambulatory patients were also enrolled in a program of supervised exercise rehabilitation. Exercises comprised leisure walking, interval training and either cycle or treadmill training, as well as upper extremity exercises. Sessions lasted for $1 \mathrm{~h}$ (with warm-up and cool down) at least three times per week. Patients were seen in the clinic three months after their return to the community and were readmitted for an overnight assessment of ventilatory support at annual intervals thereafter.

\section{Measures}

Demographic information (age, sex, diagnosis, mode of ventilation, etc), pulmonary function, daytime arterial gases, nighttime arterial oxygen saturation $\left(\mathrm{SaO}_{2}\right)$, sleep efficiency, arousal index, apnea-hypopnea index, carbon dioxide tension and 6 min walk distance were summarized. Measures were recorded at baseline, after ventilation was established, and one to two years, five years and eight to 10 years later. Pulmonary function was measured according to accepted standards for lung volumes, flow rates, diffusing capacity and respiratory muscle strength (11). Daytime arterial blood gases were measured in a standardized manner, with the subjects supine, breathing room air and unassisted. Night measures were taken from overnight respiratory polysomnographic recordings in which $\mathrm{SaO}_{2}$ and carbon dioxide tension were monitored noninvasively during sleep (12). Sleep efficiency was measured as the amount of sleep per night (first to last epoch with any wakefulness subtracted) divided by the total time in bed. The apnea-hypopnea index was expressed as the number of apneas or hypopneas/h sleep. The arousal index was expressed as the number of arousals/h sleep. Functional exercise capacity was recorded from the 6 min walk test according to a standardized protocol (13). The test was administered in a quiet, uncarpeted corridor, with the attending physical therapist providing standardized encouragement. All subjects had at least two training walks before testing. This test was performed on all ambulatory patients, even those who covered a very small distance within $6 \mathrm{~min}$. A score of 0 was not assigned to those who were not ambulatory.

\section{Statistical analysis}

Means \pm SEs were calculated for each outcome measure. To evaluate differences over time, repeated measures ANOVAs were performed ( $\mathrm{P}<0.05$ was considered significant). Post hoc analysis was performed using the Student Newman Keul's test. Because the study was retrospective, no a priori hypotheses were developed. The software handled missing data so that the repeated measures analysis was specific to each subject. Post hoc analysis for specific differences at two time points also considered only the subjects for whom data was available at these times. Statistical analysis was conducted using Sigmastat software for Windows (Version 2, SPSS Inc, USA).

\section{RESULTS}

\section{Patients with TRD}

Forty patients with TRD, aged $58 \pm 2.4$ years (mean \pm SE) were followed - 22 female patients $(55 \%)$ and 18 male patients (45\%). At the time of admission, five subjects had been ventilated under emergency circumstances, requiring intensive care management and a tracheostomy when they could not be weaned from the ventilator. The remaining 35 patients had been ventilated electively. Ventilation was noninvasive in all subjects initially, but in four subjects, a tracheostomy had subsequently been required for airway protection (one due to a cerebral vascular accident, one due to a motor vehicle accident with multiple injuries and two due to failure of the noninvasive approach). Bilevel positive airway pressure (Bi-PAP) was used in 21 subjects, and volume-cycled ventilation was used in 19 subjects. Three subjects changed from Bi-PAP to volume-cycled ventilation during the study, and one subject changed from volumecycled ventilation to Bi-PAP. One subject received continuous ventilation (for more than $20 \mathrm{~h} /$ day), five received 

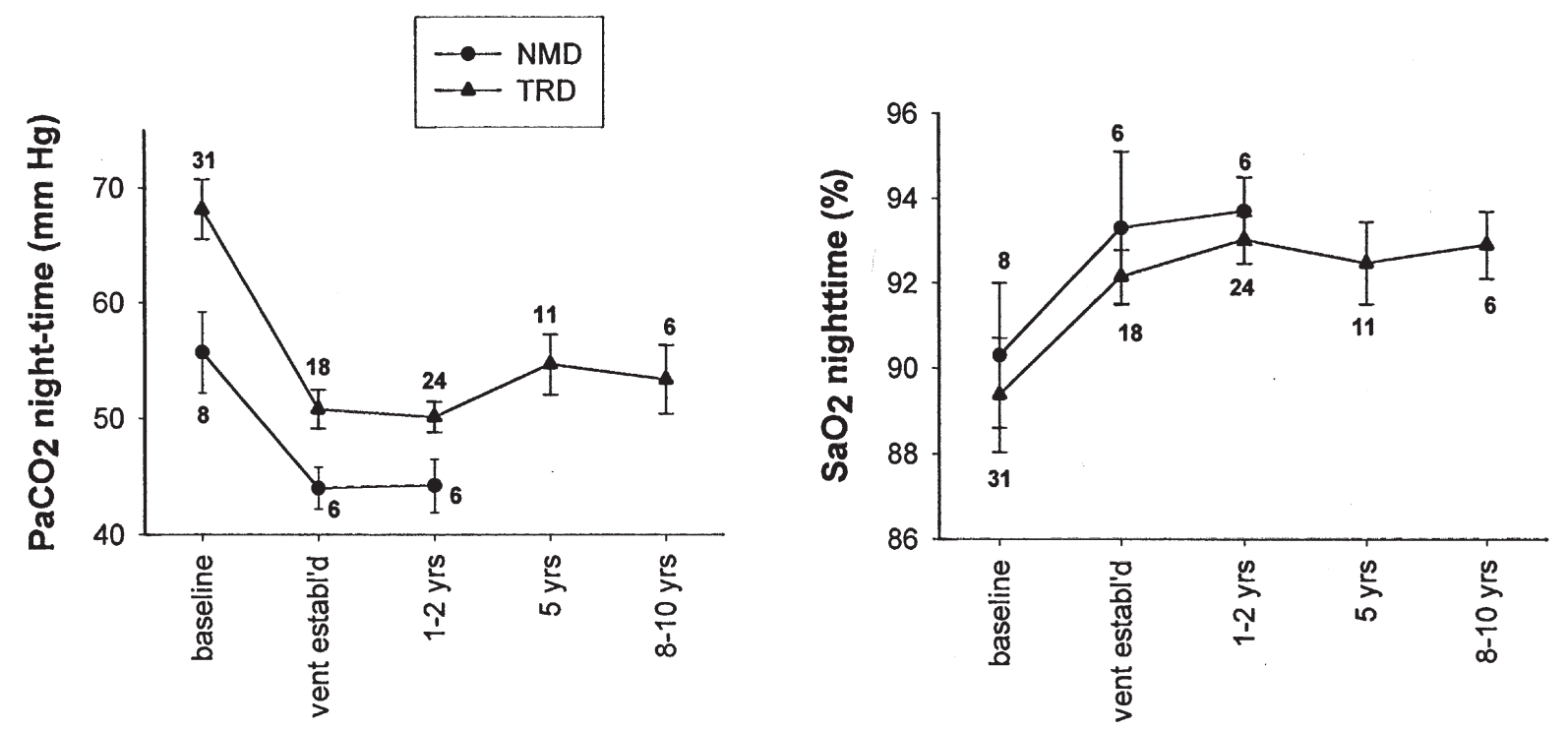

Figure 1) Transcutaneous partial pressure of arterial carbon dioxide $\left(\mathrm{PaCO}_{2}\right)$ and oxygen saturation $\left(\mathrm{SaO}_{2}\right)$ levels in patients with neuromuscular disease (NMD) (closed circles) and thoracic restrictive disease (TRD) (closed triangles). The error bars represent the SEM. The number beside each point is the sample size. Data points are joined for ease of interpretation; note, however, that the time periods between points on the $x$-axis are unequal
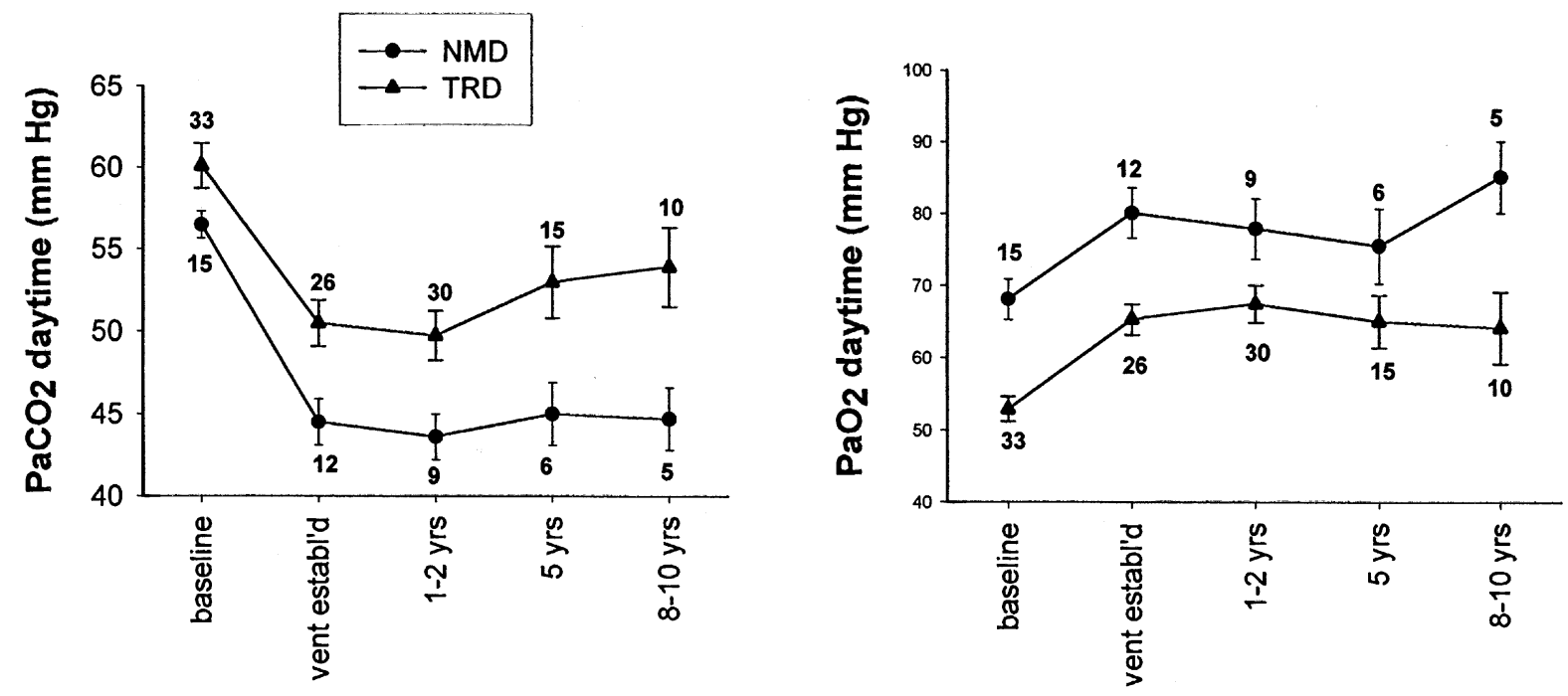

Figure 2) Daytime partial pressure of arterial carbon dioxide $\left(\mathrm{PaCO}_{2}\right)$ and partial pressure of arterial oxygen $(\mathrm{PaO})$ in patients with neuromuscular disease (NMD) (closed circles) and thoracic restrictive disease (TRD) (closed triangles). The error bars represent the SEM. The number beside each point is the sample size. Data points are joined for ease of interpretation; note, however, that the time periods between points on the $x$-axis are unequal

nighttime and some daytime ventilation (eg, during afternoon naps), and 34 received only nighttime ventilation. Two patients (5\%) died from respiratory complications during the study.

Pulmonary function tests before initiation of ventilation revealed a vital capacity (VC) of $27 \% \pm 1.6 \%$ predicted, forced expiratory volume in $1 \mathrm{~s}\left(\mathrm{FEV}_{1}\right)$ of $25 \% \pm 1.5 \%$ pre- dicted, $\mathrm{FEV}_{1} /$ forced $\mathrm{VC}$ (FVC) of $78 \% \pm 1.8 \%$, maximum inspiratory pressure at residual volume of $-35 \pm 2.9 \mathrm{~cm} \mathrm{H}_{2} \mathrm{O}$ and maximum expiratory pressure at total lung capacity of $80 \pm 8.2 \mathrm{~cm} \mathrm{H} \mathrm{H}_{2} \mathrm{O}$. There was a significant drop in $\mathrm{VC}$ $(\mathrm{P}=0.015)$ and $\mathrm{FEV}_{1}(\mathrm{P}<0.001)$ over time. On post hoc analysis, the main difference was for values of $\mathrm{VC}$ and $\mathrm{FEV}_{1}$ at 10 years compared with those immediately after 
the establishment of ventilation (drop of $5.8 \%$ in $\mathrm{VC}$ and $6.2 \%$ in $\left.\mathrm{FEV}_{1}, \mathrm{P}<0.03\right)$.

There were no significant changes in sleep efficiency, arousal index or apnea-hypopnea index among the patients (Table 1). There was a significant difference over time in the transcutaneous partial pressure of carbon dioxide $\left(\mathrm{PCO}_{2}\right)$ (Figure 1, $\left.\mathrm{P}<0.001\right)$. Post hoc analysis revealed that baseline values were significantly higher than all other values $(\mathrm{P}<0.003)$. This difference was sustained without further changes after one to two years, five years and 10 years. Despite a trend toward improvement in $\mathrm{SaO}_{2}$, the differences over time did not reach statistical significance (Figure 1, P=0.065).

With respect to daytime arterial blood gases (unassisted, breathing room air), there were significant differences over time in the partial pressure of arterial carbon dioxide $\left(\mathrm{PaCO}_{2}\right)$ level (Figure 2, $\mathrm{P}<0.001$ ). Post hoc analysis revealed that the baseline $\mathrm{PaCO}_{2}$ level was higher than the $\mathrm{PaCO}_{2}$ level after ventilation was established $(\mathrm{P}<0.001)$. The baseline $\mathrm{PaCO}_{2}$ level was also higher than the $\mathrm{PaCO}_{2}$ level one to two years $(\mathrm{P}<0.001)$ and five years $(\mathrm{P}=0.004)$ after ventilation was established. The $\mathrm{PaCO}_{2}$ level was significantly higher eight to 10 years after ventilation compared with when ventilation was established $(\mathrm{P}=0.018)$ and one to two years later $(\mathrm{P}=0.011)$. There were also significant changes in the partial pressure of arterial oxygen $\left(\mathrm{PaO}_{2}\right)$ level with time (Figure 2, $\mathrm{P}=0.001$ ), with a difference being detected between the preventilation $\mathrm{PaO}_{2}$ level and all other values $(\mathrm{P}<0.002)$.

There were significant differences in the results of the 6 min walk test over time (Figure 3, $\mathrm{P}<0.001$ ). On post hoc analysis, there was an improvement in the distance walked immediately after ventilation was established $(\mathrm{P}=0.005)$ and one to two years after $(\mathrm{P}=0.01)$ compared with baseline. There was also a decrease in the distance walked eight to 10 years after ventilation compared with when ventilation was established $(\mathrm{P}=0.002)$ and one to two years after ventilation was established $(\mathrm{P}=0.004)$.

\section{Patients with NMD}

Thirty-four individuals with NMD were included in this study. Their diagnosis varied and included muscular dystrophy $(n=8)$, amyotrophic lateral sclerosis $(n=5)$, polyneuropathy $(n=5)$, spinal cord injury $(n=4)$, postpoliomyelitis $(\mathrm{n}=3)$, myotonic dystrophy $(\mathrm{n}=2)$, cerebral palsy $(\mathrm{n}=1)$ and other undiagnosed progressive NMDs $(n=6)$. The mean age of this group of patients was $44 \pm 3.1$ years, comprising 13 female (38\%) and 21 male (62\%) patients. At the time of admission, 18 subjects had been ventilated under emergency circumstances and had received a tracheostomy in the ICU. The remaining 16 subjects had been ventilated electively using a noninvasive approach. Subsequently, four of these 16 subjects required a tracheostomy for airway protection. Thus, 22 patients $(65 \%)$ were invasively ventilated and $12(35 \%)$ were ventilated noninvasively. Eight patients were ventilated continuously (ie, for more than $20 \mathrm{~h} /$ day), and 26 patients received only nighttime ventilation. The mode of ventilation was

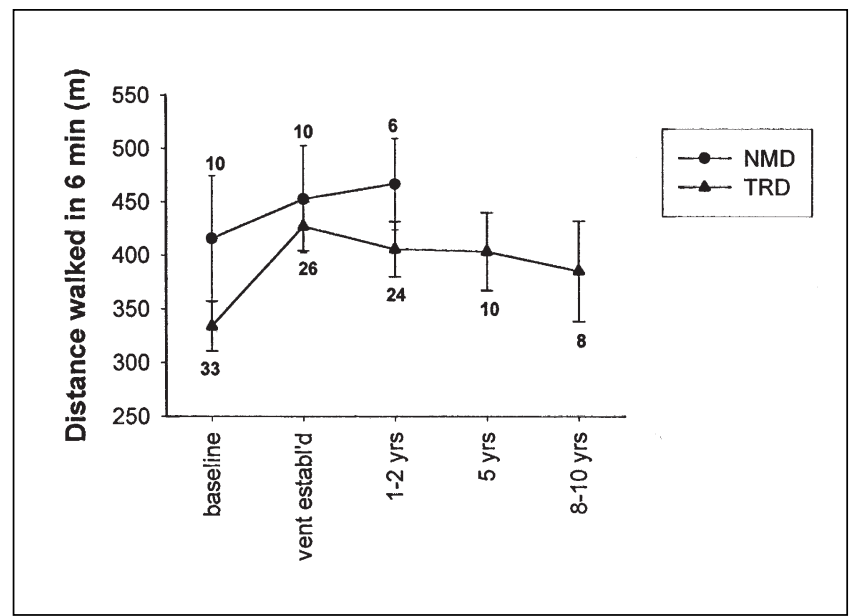

Figure 3) Distance walked in 6 min in patients with neuromuscular disease (NMD) (closed circles) and thoracic restrictive disease (TRD) (closed triangles). The error bars represent the SEM. The number beside each point is the sample size. Data points are joined for ease of interpretation; note, however, that the time periods between points on the $x$-axis are unequal

Bi-PAP in nine individuals, volume-cycled in 24 individuals and negative pressure in one individual. The latter patient was later converted to Bi-PAP. One subject was converted from Bi-PAP to volume-cycled ventilation during the study, whereas another was converted from volume-cycled ventilation to Bi-PAP. Four patients (12\%) died during the study, two from respiratory complications and two from other conditions (one from sepsis and one from a cardiomyopathy).

Pulmonary function tests at baseline (before initiation of ventilation) revealed a mean \pm SE VC of $41 \% \pm 4.9 \%$ predicted, $\mathrm{FEV}_{1}$ of $44 \% \pm 5.3 \%$ predicted and $\mathrm{FEV}_{1} / \mathrm{FVC}$ of $83 \% \pm 4.2 \%$; the maximum inspiratory pressure at residual volume was $-34 \pm 5.3 \mathrm{~cm} \mathrm{H}_{2} \mathrm{O}$, and the maximum expiratory pressure at total lung capacity was $47 \pm 10.1 \mathrm{~cm} \mathrm{H}_{2} \mathrm{O}$. These variables did not change with ventilation or one to two years after $(\mathrm{P}>0.05)$. There were insufficient data for a meaningful analysis at five years or at eight to 10 years after ventilation.

There was a significant difference over time in the nighttime transcutaneous $\mathrm{PCO}_{2}$ level $(\mathrm{P}<0.001)$ (Figure 1). There were insufficient data at five years and eight to 10 years after ventilation was established. Post hoc analysis revealed that baseline values were significantly higher than all other values $(\mathrm{P} \leq 0.004)$. Despite a trend toward improvement in the $\mathrm{SaO}_{2}$ level, the difference between groups did not reach statistical significance $(\mathrm{P}=0.067)$ (Figure 1). There was no change in sleep efficiency, arousal index or apnea-hypopnea index over time (Table 1).

The daytime $\mathrm{PaCO}_{2}$ level improved over time $(\mathrm{P}<0.001)$ (Figure 2). Post hoc analysis revealed that the baseline values for $\mathrm{PaCO}_{2}$ were significantly higher than all other values $(\mathrm{P} \leq 0.002)$. The $\mathrm{PaCO}_{2}$ level fell with ventilation and did not change further. Despite a trend toward improvement in the $\mathrm{PaO}_{2}$ level, the difference 
over time did not reach statistical significance $(\mathrm{P}=0.105)$ (Figure 2).

There was a significant difference in the 6 min walk distance over time $(\mathrm{P}=0.004)$ (Figure 3$)$. There were insufficient data at five years and eight to 10 years after ventilation was established. On post hoc analysis, the main difference was an improvement between the baseline value and the distance walked after ventilation was established $(\mathrm{P}=0.003)$.

\section{DISCUSSION}

A unit dedicated to the management of patients requiring long term ventilation at home can be a useful asset in the care of patients with chronic respiratory failure. Our experience is that the presence of this unit has resulted in a streamlined training and follow-up program outside of the acute care setting. Our experience supports and extends those reports that detail the improvement of blood gases with long term ventilation at home $(4,14-17)$. In this unit, the patients were assessed and trained for home ventilation. As soon as the ventilation was well established, they were enrolled in a respiratory rehabilitation program to provide education, increase exercise capacity and stabilize their respiratory status. Patients with TRD and those with NMD who were still ambulatory participated in a supervised exercise program. Patients with NMD who were no longer ambulatory were assessed for devices that could increase functional independence.

Not all of the outcome measures were available each time. The duration and completeness of follow-up depended, at least in part, on the patient's clinical and psychosocial situation. Although we did not document the clinical reasons for nonattendance for each subject, the reasons were mainly medical in nature (eg, respiratory exacerbation) or psychosocial (eg, lack of motivation, absence of transportation). We only accepted data from within three months of the exact yearly date. Because the outcome measures were not made by the same staff member, there may have been some variability in their quality and precision. However, measures such as daytime arterial blood gases, nighttime noninvasive gas tensions and sleep architecture were collected using established, standardized procedures. Measures of pulmonary function were always made by trained, accredited technologists, and walking tests were carried out by physical therapists experienced in such measures. The presence of a control group (no ventilation) of similar baseline status would have strengthened the conclusions. However, such studies are difficult to design, especially because mechanical ventilatory support may be life-saving. Some measures such as functional exercise capacity were more influenced by the underlying diagnosis (NMD) than by the process of ventilatory support. Because patients with NMD frequently deteriorate, many patients were unable to complete the walking test after two years of follow-up.

Despite the application of an equipment interface (mask or tracheostomy), as well as the attendant restrictions in movement and posture, HMV did not substantially impair sleep architecture. In a review of 138 patients with mixed obstructive and nonobstructive conditions treated with nasal intermittent positive pressure ventilation (NIPPV), Simonds and Elliott (15) noted that $67 \%$ of patients rated their sleep as 'average', and 21\% described it as 'very good'. Only $5 \%$ of ventilated patients rated their sleep quality as 'poor'. Leger and colleagues (14), in a review of 276 patients ventilated with NIPPV, noted that $62 \%$ of patients reported that their sleep had improved despite the use of the mask and the noise of the ventilator.

Home ventilation can be sustained for long periods. Only two of 44 patients with TRD (5\%) died, and the remainder continued to receive ventilatory support on a nightly basis. Of those with NMD, only four of 34 (12\%) died, despite the progressive nature of their underlying conditions. None required prolonged hospitalization. It is our view that a dedicated unit with an experienced and skilled multidisciplinary team allows such patients to remain in the community. Frequent follow-up assessments of daytime and nighttime gas exchange allows for prompt intervention if problems occur.

Reports of HMV are difficult to compare due to variations in the type of ventilation (positive versus negative) and in the diagnostic mix of the subjects. Simonds and Elliot (15) reported that in patients with domiciliary NIPPV, the probability of continuing ventilation for five years was 79\% among patients with TRD, 94\% among those post-tuberculosis, $100 \%$ among those who were postpoliomyelitis and $81 \%$ among those with NMD. Splaingard and colleagues (18) reviewed 26 adults and 21 children who received positive pressure ventilation via a tracheostomy and in whom survival differed between those with or without spinal injury (three-year survival rate $63 \%$ and $74 \%$, respectively). In their report of negative pressure ventilation for adults with NMD, Splaingard and colleagues (19) noted that their five-year survival rate was $76 \%$. A review of 51 patients with nonobstructive ventilatory failure, most of whom received negative pressure ventilation, noted a twoyear survival rate of $90 \%$ (20). When predictors of survival for subjects with HMV were reported, patients with TRD or NMD were noted to survive longer than those with chronic obstructive pulmonary disease (COPD) (21). The presence of obstructive lung disease was associated with a worse prognosis, irrespective of the other diagnoses (21).

Ongoing HMV likely contributed to the observed stability in pulmonary function, with only a small reduction in $\mathrm{VC}$ of $5.8 \%$ over 10 years for subjects with TRD and no observed change after two years for subjects with NMD. This is in keeping with a report by Baydur and colleagues (22) in which there was a remarkably slow decline $(5 \mathrm{~mL} /$ year or $0.1 \%$ predicted/year) in $\mathrm{VC}$ among 25 postpoliomyelitis subjects who received negative pressure ventilation and an observed increase in VC during a two-year period among those who subsequently received NIPPV by mask. For patients with Duchenne's muscular dystrophy (DMD), Baydur and colleagues (22) noted that the decline in lung function was more rapid, with a fall of $60 \mathrm{~mL} /$ year during a two-year period. 
Improved daytime blood gases have been noted in a number of short term studies of NIPPV and in at least one large follow-up study of 276 patients with a variety of diagnostic categories (14). In the series by Leger et al (14), patients with NMD treated with NIPPV were noted to have had a higher $\mathrm{PaO}_{2}$ level than patients with TRD $(75 \pm 16 \mathrm{mmHg}$ and $54 \pm 10 \mathrm{mmHg}$, respectively). This difference was maintained, even though both groups demonstrated an improvement in $\mathrm{PaO}_{2}$ level one to two years postventilation. The improved gas exchange was associated with a decrease in hospitalization for respiratory illness. In 56 patients with TRD, the number of days spent in hospital decreased from $34 \pm 31$ days for the year before ventilation to $6 \pm 6$ days for the year after initiating NIPPV. Our results also indicated that patients with NMD had a higher $\mathrm{PaO}_{2}$ level during the day and a better $\mathrm{SaO}_{2}$ level at night (before ventilation and over the next several years) than those with TRD. Similarly, the nighttime and daytime $\mathrm{PaCO}_{2}$ levels were lower in patients with NMD than in those with TRD. These observations were consistent with the underlying pathology of TRD, in which the chest and lung recoil are increased, whereas in NMD, recoil is often diminished.

The mechanisms of improvement after HMV are multifactorial. Subjects may have benefited from the daily resting of dysfunctional respiratory muscles during the period of ventilatory support $(4,6)$. Respiratory system compliance probably improved as a result of better inflation, thereby reducing the work of breathing (4). Chemoreceptor sensitivity to carbon dioxide was likely reset after daily hours of close to normal arterial blood gas tensions $(16,17)$. Peripheral muscles may also have benefited from the improved milieu, resulting in an improved functional exercise capacity.

Improved arterial gases have been closely linked to improved survival $(14,17,23-25)$. Although there have been no randomized, controlled trials of NIPPV in TRD, at least one report published before the current approaches of mechanical ventilatory support indicated that when left untreated, close to $50 \%$ of patients with severe TRD and respiratory failure died within one year (26).

Although NIPPV is clearly an attractive and effective alternative to tracheostomy, 22 of 34 patients with NMD under our care did require a tracheostomy at some point in their clinical course. Our current policy is to commence ventilation noninvasively whenever possible. However, many individuals had already had a tracheostomy at the time of their referral to our unit, which often followed prolonged ventilation in the ICU. Provided that they could protect their airway, we considered decannulation in all such individuals. In this series, decannulation was infrequent for several reasons. First, patients often came with well established tracheostomies in place for several months; second, swallowing studies often reflected ongoing aspiration; and third, patients and families were resistant to changing from a system that was comfortable and perceived to be safe. Baydur et al (22) noted that of 73 patients with NMD, 56\% of those with postpoliomyelitis and $67 \%$ of those with DMD eventually required a tracheostomy. Leger and colleagues (14) reported that 31\% of patients (five of 14) with DMD required a tracheostomy. In contrast, NIPPV has been used successfully to maintain ongoing ventilatory support for severely compromised patients with NMD who had almost no ventilator-free time (27).

In keeping with the improved nighttime and daytime gases, ambulatory patients with TRD also improved their functional exercise capacity (6 min walk) postventilation. This improvement was maintained for several years; they walked $334 \mathrm{~m}$ at baseline and $426 \mathrm{~m}$ at one to two years after ventilation was established. These distances compared well with 6 min walking distances recorded among healthy volunteers, which ranged from 494 to $631 \mathrm{~m}(28,29)$. In NMD, the improvement was more difficult to ascertain due to the small sample size and lack of follow-up data. Although we did not formally measure activities of daily living, they have been reported to improve in $70 \%$ of patients with NIPPV (14). After administering a single measure of health status (SF36), Simonds and Elliott (15) noted that physical function was consistently higher in patients with TRD, postpoliomyelitis and previous tuberculosis compared with ventilated patients with COPD. Although patients with NMD and COPD had similar levels of physical function, the role limitations were greater in the COPD group. Health status outcome in patients with NIPPV was comparable with nonventilated patients with chronic conditions. Although physical function was reduced compared with normative United Kingdom values, patients receiving NIPPV had similar mental health, energy and vitality scores. Despite the fact that most patients with NMD had progressive conditions with increasing functional limitations, the ongoing supervision of the multidisciplinary team enabled patients to be introduced to appropriate mobility aids such as power wheelchairs adapted for ventilator users and electronic environmental controls. These devices, together with the clinical stability achieved with HMV, enabled the patients to sustain consistent functional mobility, to direct their own care and to continue to live independently.

An assessment of quality of life would have been valuable. In fact, we have quality of life scores for several of the subjects. However, many of the subjects were enrolled in the study 10 years previously, when quality of life measures were not readily available or commonly used. Thus, most patients had measures of quality of life at only one point in time, making it difficult to interpret any change over time. We therefore chose to exclude these data.

Clearly, there may be a referral bias, because our report only included those who were accepted to the home ventilation program. Thus, we have excluded those who refused home ventilation, those who were ineligible and those who were institutionalized due to lack of social support to allow them to return to their homes. Nevertheless, our clinical impression is that our findings can be generalized to individuals who return to the community in a clinically stable state, those who have received training and those who have social support systems. We used the criteria developed by the American College of Chest Physicians (2) in 1998 to help to identify appropriate recipients for home ventilation. 


\section{CONCLUSIONS}

A well-structured home ventilation training and follow-up program was associated with prolonged improvements in gas exchange. In a smaller number of ambulatory patients with TRD, exercise tolerance also improved.

\section{REFERENCES}

1. Dunkin LJ. Home ventilatory assistance. Anaesthesia 1983;38:644-9.

2. Make BJ, Hill NS, Goldberg AI, et al. Mechanical ventilation beyond the intensive care unit. Report of a consensus conference of the American College of Chest Physicians. Chest 1998;113(Suppl 5):289S-344S.

3. Muir J-F. Home mechanical ventilation. In: Simond AK, Muir J-F, Person DJ, eds. Pulmonary Rehabilitation. London: BMJ Publishing Group, 1996.

4. Turkington PM, Elliott MW. Rationale for the use of non-invasive ventilation in chronic ventilatory failure. Thorax 2000;55:417-23.

5. Janssens JP, Kehrer PH, Chevrolet JC, Rochat T. Non-invasive home ventilation (NHV): Analysis of 32 cases with an average 41-months follow-up. Rev Mal Respir 1999;16:511-20.

6 . Road J. Assisted ventilation for chronic neuromuscular disorders. Thorax 2000;55:1-2.

7. O'Donahue WJ Jr, Giovannoni RM, Goldberg AI, et al. Long-term mechanical ventilation. Guidelines for management in the home and at alternate community sites. Report of the Ad Hoc Committee, Respiratory Care Section, American College of Chest Physicians. Chest 1986;90(Suppl 1):1-37.

8. Adams AB, Whitman J, Marcy T. Surveys of long-term ventilatory support in Minnesota: 1986 and 1992. Chest 1993;103:1463-9.

9. Litwin PD, Flegel CM, Richardson BC. An overview of home mechanical ventilation in Canada. Can J Respir Ther 1991;28:67-73.

10. Polkey MI, Lyall RA, Davidson AC, Leigh PN, Moxham J. Ethical and clinical issues in the use of home non-invasive mechanical ventilation for the palliation of breathlessness in motor neurone disease. Thorax 1999;54:367-71.

11. American Thoracic Society. Standardization of spirometry 1987 update. Am Rev Respir Dis 1987;136:1285-98.

12. Rechtschaffen A, Kales A, eds. A manual of standardized terminology, techniques and scoring system for sleep stages of human subjects. US Department of Health and Welfare, Public Health Service, National Institute of Health. Washington, DC: US Government Printing Office, 1968.

13. Guyatt GH, Pugsley SO, Sullivan MJ, et al. Effect of encouragement on walking test performance. Thorax 1984;39:818-22.

14. Leger P, Bedicam JM, Cornette A, et al. Nasal intermittent positive pressure ventilation. Long-term follow up in patients with severe chronic respiratory insufficiency. Chest 1994;105:100-5.
ACKNOWLEDGEMENTS: Supported in part by the Clinical Evaluation and Research Unit at the West Park Healthcare Centre and by the West Park Healthcare Centre Foundation (Toronto, Ontario). The authors would like to acknowledge $\mathrm{Mr}$ Tom Dolmage for his assistance in data analysis and Ms Diane Peterson for her assistance with manuscript preparation.

15. Simonds AK, Elliott MW. Outcome of domiciliary nasal intermittent positive pressure ventilation in restrictive and obstructive disorders. Thorax 1995;50:604-9.

16. Muir J-F. Home mechanical ventilation. Thorax 1993;48:1264-73.

17. Hill NS. Noninvasive ventilation: does it work, for whom, and how? Am Rev Respir Dis 1993;147:1050-5.

18. Splaingard ML, Frates RC, Harrison GM, Carter RE, Jefferson LS. Home positive-pressure ventilation. Twenty years' experience. Chest 1983;84:376-82.

19. Splaingard ML, Frates RC, Jefferson LS, Rosen CL, Harrison GM. Home negative pressure ventilation: report of 20 years of experience in patients with neuromuscular disease. Arch Phys Med Rehabil 1985;66:239-42.

20. Sawicka EH, Loh L, Branthwaite MA. Domiciliary ventilatory support: an analysis of outcome. Thorax 1988;43:31-5.

21. Chailleux E, Fauroux B, Binet F, Dautzenberg B, Polu J-M. Predictors of survival in patients receiving domiciliary oxygen therapy or mechanical ventilation. A 10-year analysis of ANTADIR Observatory. Chest 1996;109:741-9.

22. Baydur A, Layne E, Aral H, et al. Long term non-invasive ventilation in the community for patients with musculoskeletal disorders: 46 year experience and review. Thorax 2000;55:4-11.

23. Garay SM, Turino GM, Goldring RM. Sustained reversal of chronic hypercapnia in patients with alveolar hypoventilation syndromes. Long-term maintenance with noninvasive nocturnal mechanical ventilation. Am J Med 1981;70:269-74.

24. Mohr CH, Hill NS. Long-term follow up of nocturnal ventilatory assistance in patients with respiratory failure due to Duchenne-type muscular dystrophy. Chest 1990;97:91-6.

25. Leger P, Jennequin J, Gerard M, Robert D. Home positive pressure ventilation via nasal mask for patients with neuromuscular weakness or restrictive lung or chest-wall disease. Respir Care 1989;34:73-7.

26. Bergofsky EH. Respiratory failure in disorders of the thoracic cage. Am Rev Respir Dis 1979;119:643-69.

27. Bach JR, Barnett V. Ethical considerations in the management of individuals with severe neuromuscular disorders. Am J Phys Med Rehabil 1994;73:134-40.

28. Troosters T, Gosselink R, Decramer M. Six minute walking distance in healthy elderly subjects. Eur Respir J 1999;14:270-4.

29. Enright PL, Sherrill DL. Reference equations for the six-minute walk in healthy adults. Am J Respir Crit Care Med 1998;158:1384-7. 


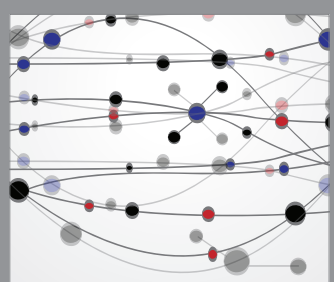

The Scientific World Journal
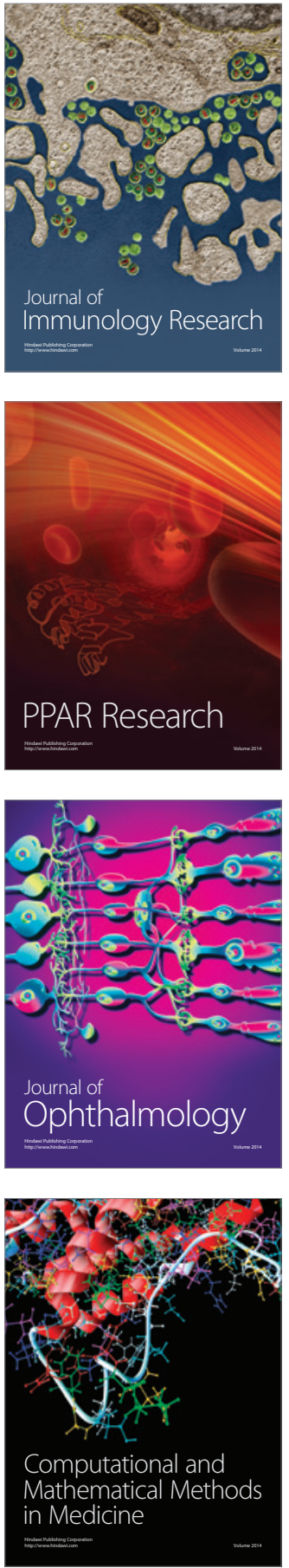

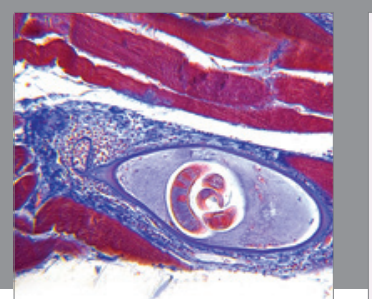

Gastroenterology Research and Practice

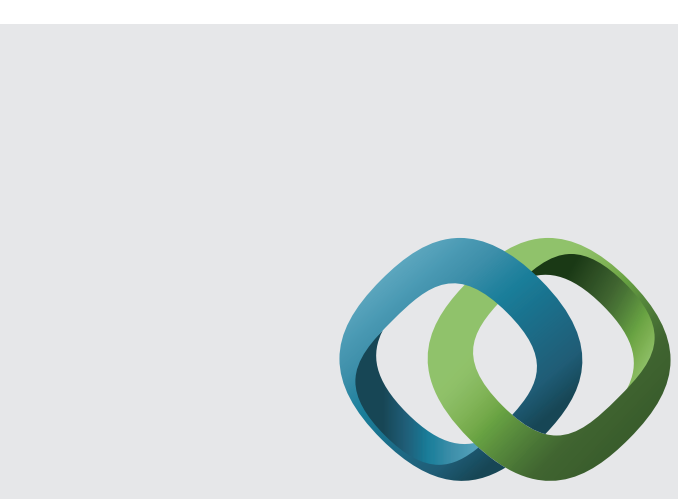

\section{Hindawi}

Submit your manuscripts at

http://www.hindawi.com
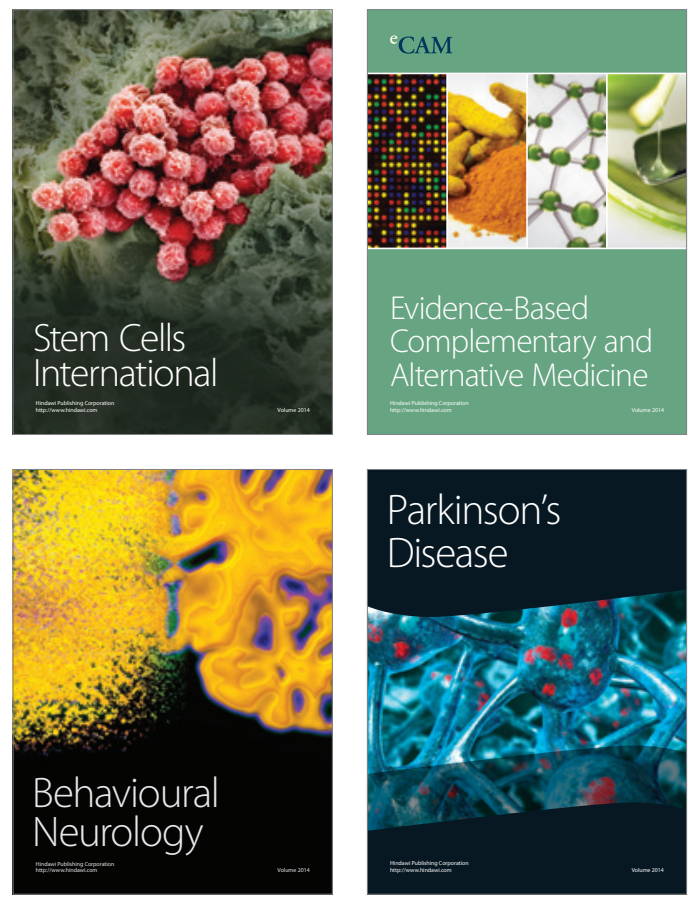
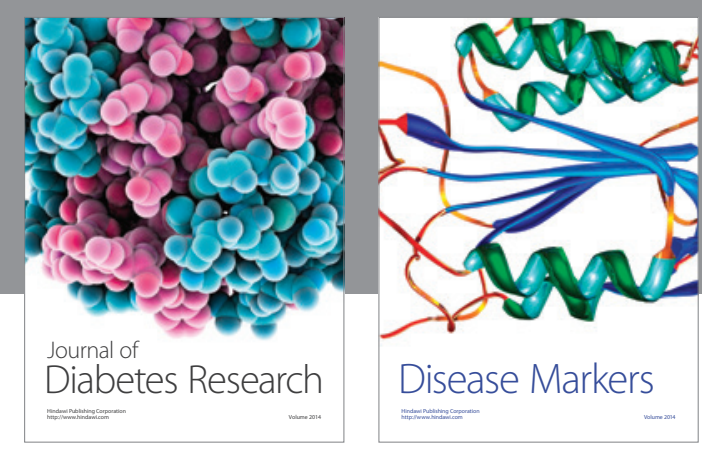

Disease Markers
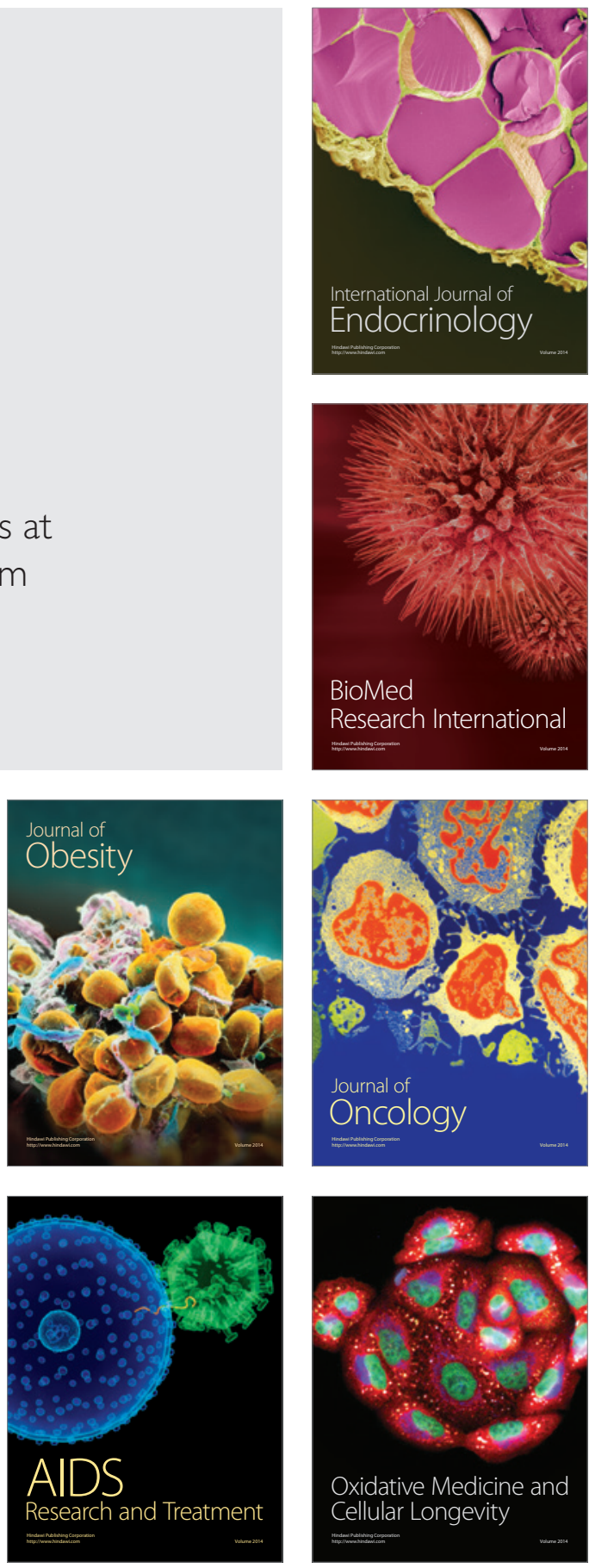